\title{
Comparison of Risk Factors \& Angiographic Profiles between Young Patients with ST Segment Elevation Myocardial Infarction and Non-ST Segment Elevation Myocardial Infarction
}

Sayeedur Rahman Khan ${ }^{1}$, Fazila-Tun-Nesa Malik², Mir Nesaruddin Ahmed ${ }^{3}$, Asim Kumar Biswas ${ }^{4}$, Mainul Islam $^{5}$, Bivash Kumer Sheel ${ }^{6}$, Sharmin Tahmina Khan ${ }^{7}$, Hasan Mahmud Iqbal ${ }^{8}$, Md. Rafiqul Islam ${ }^{9}$

\begin{abstract}
:
Background: Coronary artery disease is the leading cause of death in the world. Advancing age is a well-recognized risk factor for acute myocardial infarction (AMI). Myocardial infarction is less common in young adults. Prevalence of acute coronary syndrome in young individuals is increasing progressively. These patients have different risk profile, presentation and prognosis. Early recognition and risk factor modification in this population sub-set is of key importance. Objectives: The purpose of the present study was to determine the differences in risk factors and coronary angiographic profile of young patients with ST-segment elevated myocardial infarction (STEMI) vs. those with non-ST-segment elevated myocardial infarction (NSTEMI). Methods: In this cross sectional analytical study total 135 patients (70 STEMI and 65 NSTEMI) aged $\leq 45$ years were enrolled to see the differences of risk factors and angiographic profile. Results: The mean age of the study population was $39.39 \pm 5.12$ years and the
\end{abstract}

study showed male predominance $(90.40 \%$ was male and $9.60 \%$ was female). Smoking/tobacco consumption was significantly higher in STEMI patients, whereas diabetes mellitus and hypertension were more prevalent in NSTEMI patients. The frequency of single vessel disease and involvement of left anterior descending artery was significantly higher in young STEMI patients. In case of young NSTEMI patients frequency of triple vessel disease, noncritical coronary artery disease and involvement of left circumflex coronary was significantly higher. The frequency of double vessel disease and involvement of left main coronary artery was also nonsignificantly higher in young NSTEMI patients. There was no significant difference regarding involvement of right coronary artery. Conclusion: There are significant differences between young STEMI and young NSTEMI patients in respect to risk factors and angiographic profile. Key words: Young patient, STEMI, NSTEMI, Risk factors, Coronary angiographic profile.

(Bangladesh Heart Journal 2021; 36(2): 124-132)

Introduction

Ischemic heart disease is a major public health problem coronary syndrome is a common presentation of associated with high morbidity and mortality. Acute ischemic heart disease ${ }^{1}$. It is also the single largest

1. Medical Officer, Department of Cardiology, NICVD

2. Professor \& Chief Consultant, Department of Cardiology, NHFH\&RI

3. Associate Professor, Department of Cardiology, NHFH\&RI

4. Assistant Professor, Department of Cardiology, $\mathrm{SBMCH}$

5. Assistant Registrar, Department of Cardiology, NICVD

6. Assistant Registrar, Department of Pediatric Cardiology, NICVD

7. Registrar, Department of Gastroenterology, SRNGIH

8. Junior Consultant, Civil Surgeon Office, Cumilla

9. Senior Medical Officer, Department of Cardiology, NHFH\&RI

Address of Correspondence: Dr. Sayeedur Rahman Khan, Medical Officer, NICVD, Dhaka, Bangladesh. E-mail: dr.rumibd@gmail.com

DOI: https://doi.org/10.3329/bhj.v36i2.56038

Copyright $\odot 2017$ Bangladesh Cardiac Society. Published by Bangladesh Cardiac Society. This is an Open Access articles published under the Creative Commons Attribution-NonCommercial 4.0 International License (CC BY-NC). This license permits use, distribution and reproduction in any medium, provided

the original work is properly cited and is not used for commercial purposes. 
cause of death in developed countries as well as developing countries ${ }^{2}$. Risk of CAD among Asian Indians is 3-4 times higher than white Americans, 6 times higher than Chinese, and 20 times higher than Japanese counterparts ${ }^{3}$.

Coronary artery disease (CAD) is leading cause of mortality worldwide and by the year 2020, will be first in the leading causes of disability ${ }^{4}$. While the death rates have been declining for the past three decades in the west, these rates are rising in India. In the last three decades, the prevalence of CAD has increased from $1.1 \%$ to about $7.5 \%$ in the urban population and from $2.1 \%$ to $3.7 \%$ in the rural population ${ }^{5}$. CAD tends to occur at a younger age in Indians, with more extensive angiographic involvement, contributed genetic, metabolic, conventional and nonconventional risk factors $6,7,8$.

The alarming face of this eminent issue is that nearly $80 \%$ of total $\mathrm{CV}$ deaths occur in low and middle income countries including Bangladesh ${ }^{9}$. Bangladesh is experiencing steep and sustained increases in the incidence of CAD during recent decades ${ }^{10}$. The burden of $\mathrm{CHD}$ is emerging as a public health concern in developing countries like Bangladesh ${ }^{11}$. The exact prevalence of CAD in Bangladesh is not known. Only a limited number of small-scale epidemiological studies are available. Probably the prevalence of IHD was first reported in 1976, which was $0.33 \%{ }^{12}$. More recent data indicates CAD prevalence to be $3.4 \%$ in rural and $19.6 \%$ in an urban sample of working professionals ${ }^{13,14}$. In Bangladesh, ACS is the major presenting form of CAD and accounts for $45 \%$ of all cause cardiac hospitalization ${ }^{15}$.

Coronary artery disease (CAD) is relatively less common in subjects below 40 years of age, as it occurs in about $6-10 \%$ of them but it has grave medical, social, psychological, and economic consequences in this age group. With rapid civilization changes and increasing prevalence of conventional risk factors for CAD, premature atherosclerosis is a growing problem, occurring in even younger age groups including those in the third and fourth decade of life ${ }^{16}$. Although the aetiology of CAD in young subjects is related to coronary atherosclerosis in $80 \%$ of cases, a number of differences regarding both the risk factor profile and clinical and angiographic characteristics exist in comparison to older patients ${ }^{17,18}$.

Sedentary life style and higher consumption of calories, saturated fat, tobacco and alcohol contribute to obesity, dyslipidaemia, hypertension (HTN), diabetes mellitus (DM) and hyperuricaemia and increase the risk of early onset $\mathrm{Ml}$ in Indian population ${ }^{19}$.
Like all other developed and developing countries, prevalence and incidence of type $2 \mathrm{DM}$ is increasing in Bangladesh and this will place Bangladesh among the top seven countries in terms of the number of people living with diabetes in $2030^{20}$.

In a study in Bangladesh smoking was found as the most common risk factor of acute myocardial infarction among young patients followed by dyslipidaemia, hypertension \& diabetes. Single vessel coronary artery disease was the most common lesion in both male \& female followed by double vessel coronary artery disease and triple vessel coronary artery disease. In case of female triple vessel coronary artery disease was more than double vessel coronary artery disease ${ }^{21}$. Another study also revealed the smoking as most frequent risk factor of acute myocardial infarction with majority patients having single vessel disease and most frequently involve vessel is $L A D^{22}$.

Tobacco consumption is quite common in Bangladesh: prevalence is $51.0 \%$ for any form, $26.2 \%$ for smoking and $31.7 \%$ for smokeless tobacco ${ }^{23}$. In a recently published study, betel quid chewing was found in $33.2 \%$ of rural population ${ }^{24}$. Bangladesh is one of the top 10 countries that make-up two-thirds of the world population of smokers ${ }^{25}$.

As a result of socioeconomic transition, lifestyle, as well as, the dietary pattern are changing in Bangladesh. Increasing prevalence of obesity, tobacco use, high intake of processed foods and less physical activity accompany the transition ${ }^{14}$. In general, $21.5 \%$ adults (male $21 \%$, female $22 \%$ ) have body-mass index (BMI) $\geq 25 \mathrm{~kg} / \mathrm{m}^{2}$. Increased waist circumference is alarming, especially in women $(33.7 \%)^{23}$. Visceral fat typical of android obesity has a greater association with metabolic syndrome, hyperinsulinemia and CAD in both men and women ${ }^{26}$.

According to the KAMIR (Korea Acute Myocardial Infarction Registry) study STEMI patients were younger, more likely to be men and smokers, and had poorer left ventricular function with a higher incidence of cardiac death, compared to NSTEMI patients ${ }^{27}$. NSTEMI patients had a higher prevalence of 3- vessel and left main coronary artery disease with complex lesions, and were more likely to have co morbidities ${ }^{28}$.

Comparative analysis of young patients from South India with STEMI and NSTEMI revealed that single-vessel disease was significantly more common in the STEMI group, whereas triple-vessel disease was significantly more common in the NSTEMI group. Smoking/tobacco consumption was the most significant coronary risk factor 
in both groups. On the other hand, hypertension and diabetes were common among young patients with NSTEMI ${ }^{29}$.

It has also been noted that the clinical presentation, risk factor profile, and coronary anatomy of young patients who develop CAD differs to those who develops CAD at an older age 1,30 . Overall, these studies have indicated that patients with early onset of CAD exhibit preponderance of single vessel disease, and dominance of coronary risk factors such as hypercholesterolemia, family history of CAD, and cigarette smoking as compared to older patients.

However, there have been very limited data to compare demographic and angiographic characteristics in young patients stratified according to the type of acute coronary syndrome. Therefore, this study aimed to identify the differences between risk factors profile and coronary angiographic characteristics of young adults presenting with ST-segment elevation myocardial infarction (STEMI) and non-ST-segment elevation myocardial infarction (NSTEMI). To define "young patient" an age cut-off of 45 years and below was taken, which was based on previous studies $31,32,33,34,35$.

\section{Materials and Methods:}

This observational study was carried out in the department of cardiology, National Heart Foundation Hospital and Research Institute, Dhaka from July, 2016 to June, 2017. Patients who got admitted with the clinical diagnosis of STEMI \& NSTEMI and underwent coronary angiography at the index event from July, 2016 to June, 2017 were study population. Considering inclusion \& exclusion criteria 135 patients were selected having STEMI \& NSTEMI. Patients were divided into two groups according to the type of myocardial infarction.

Group 1: patients who were admitted with STEMI \& underwent coronary angiography (STEMI group) and

Group 2: patients who were admitted with NSTEMI \& underwent coronary angiography (NSTEMI group).

\section{Enrolment of subjects}

\section{Inclusion Criteria:}

1. Both male \& female patients who were admitted with STEMI or NSTEMI and underwent coronary angiography.

2. Age $\leq 45$ years

\section{Exclusion Criteria:}

1. Age $>45$ years

2. Patient with history \& evidence of previous ACS (STEMI/NSTEMI/UA).

3. Past History of PTCA or CABG
4. All patients of valvular heart disease and congenital heart disease.

5. Concomitant co-morbid conditions (severe liver \& kidney diseases)

6. Patient who did not give consent.

\section{Study Procedure}

All patient aged $\leq 45$ years who were admitted in the Department of cardiology, NHFH \& RI, Dhaka fulfilling the inclusion and exclusion criteria were considered as study population. Meticulous history was taken regarding symptoms (chest pain, shortness of breath or other features) and detailed clinical examination was performed in each patient. Demographic and anthropometric data such as age, sex, height $(\mathrm{cm})$, weight $(\mathrm{Kg})$, BMI $(\mathrm{Kg} / \mathrm{m} 2)$ were noted. Coronary risk factors of all patients were recorded. Blood sample was taken for Troponin I, CK MB, Blood sugar, Serum creatinine and fasting lipid profile. Patient's baseline 12 lead ECG \& Echocardiography were performed. Patients were divided into 2 groups according to clinical diagnosis of STEMI \& NSTEMI. After coronary angiogram, findings of involved vessel, site of lesion, \% of stenosis, number of vessel involvement were analyzed between the groups.

\section{Data Collection}

Data were collected in a predesigned data collection form.

\section{Stastistical Analysis}

After processing all available data, statistical analysis of their significance were done. Obtained data were expressed in frequency, percentage, mean and standard deviation as applicable. Comparison between groups were done by Student's T-test for continuous variables. Categorical data were analyzed by chi-square test. The whole analysis was done with the help of computer based SPSS (Statistical programme for social science) programme version 23.0. P-value of $<0.05$ was considered as significant.

\section{Observation and Results}

The purpose of the present study was to determine the differences in risk factors and coronary angiographic profile of young patients with ST-segment elevated myocardial infarction (STEMI) vs. those with non-STsegment elevated myocardial infarction (NSTEMI). Considering inclusion and exclusion criteria total number of 135 patients (70 STEMI and 65 NSTEMI) aged $\leq 45$ years were studied. Observations and results are presented in different tables and diagrams. 


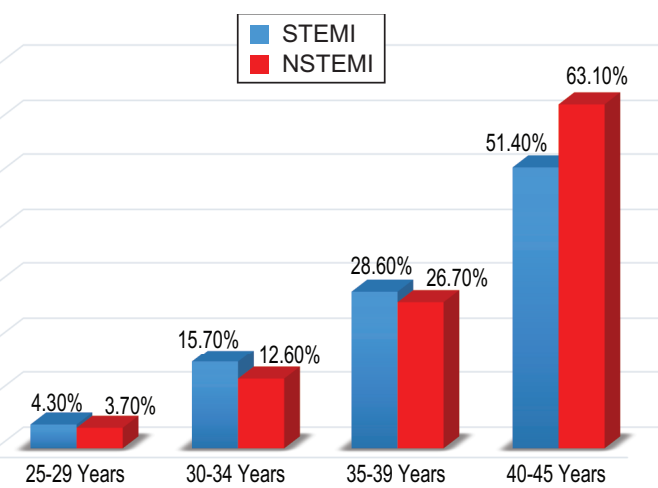

Fig.-1: Bar diagram showing comparison of age distribution in between study groups ( $n=135)$

Most of the patients belong to $40-45$ years age group ( $51.4 \%$ in STEMI and $63.1 \%$ in NSTEMI). The mean age was $39.39 \pm 5.12$ years and the range was $25-45$ years. There was no statistically significant difference between the study groups in terms of age $(p>0.05)$

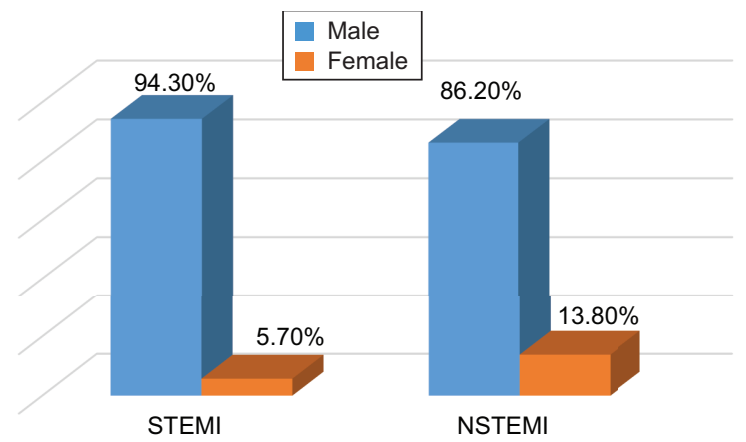

Fig.-2: Bar diagram showing sex distribution in between study groups $(n=135)$

This study shows male predominance, of all patients $90.40 \%$ (122) was male and $9.60 \%$ (13) was female. Analysis revealed there was no statistically significant difference between two study groups $(p>0.05)$
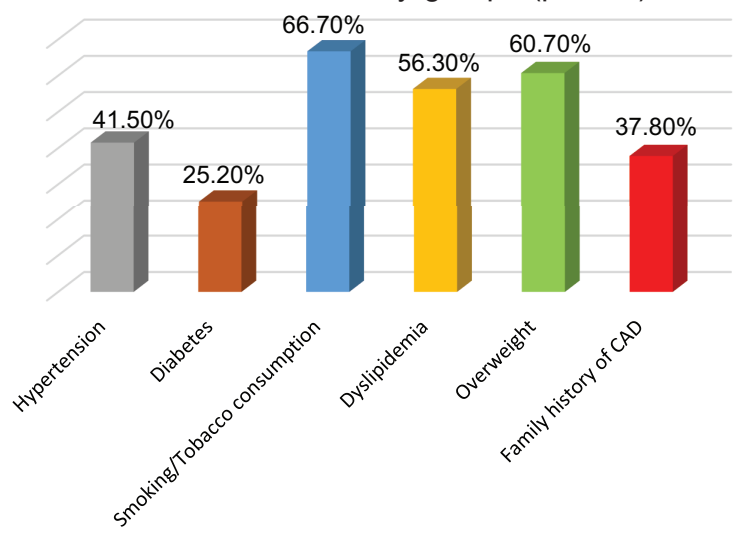

Fig.-3: Bar diagram showing distribution of risk factors of study population $(n=135)$
Smoking/tobacco consumption was $66.7 \%$, dyslipidemia was $56.3 \%$, hypertension was $42.5 \%$, diabetes mellitus was $25.2 \%$, family history of CAD was $37.8 \%$ and overweight was $60.7 \%$.

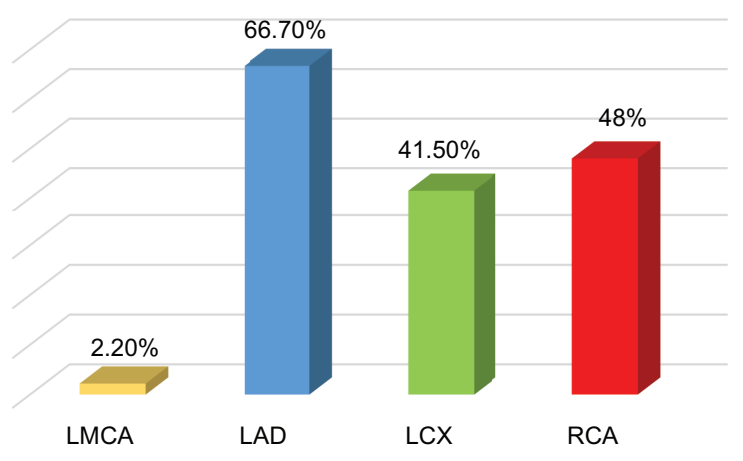

Fig.-4: Bar diagram showing distribution of involved vessel in study population $(n=135)$

LAD $(66.7 \%)$ was the most commonly involved vessel followed by RCA (48\%) and LCX (41.5\%). LM (2.2\%) was the less commonly involved vessel. Due to multivessel involvement total percentage is more than $100 \%$.

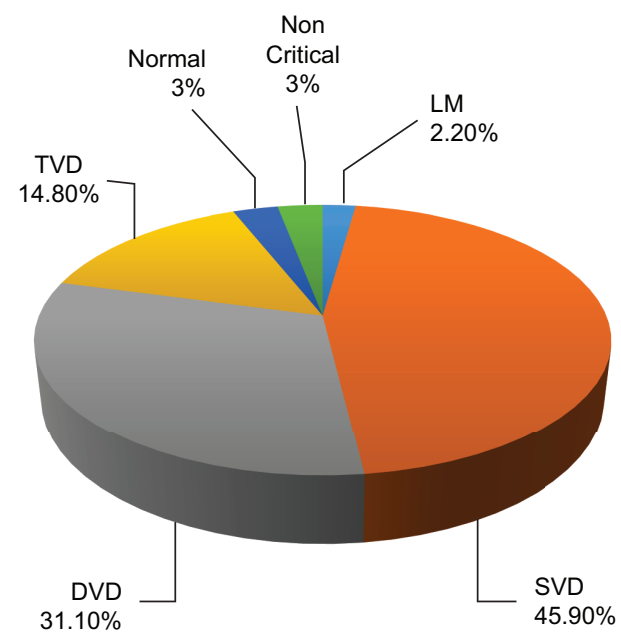

Fig.-5: Pie chart showing distribution of number of involved vessels in study population $(n=135)$

SVD was found in $45.9 \%$ cases, DVD was found in $31.1 \%$ cases, TVD was found in $14.8 \%$ cases, LMCA was found in $2.2 \%$ cases, normal coronary artery was found $3 \%$ cases and non-critical coronary artery lesion was found in $3 \%$ cases. The most common coronary lesion was SVD. 
Table-I

Comparison of distribution of risk factors in between study groups $(n=135)$

\begin{tabular}{|c|c|c|c|c|c|}
\hline \multirow[t]{2}{*}{ Risk factors } & \multicolumn{2}{|c|}{$\operatorname{STEMI}(n=70)$} & \multicolumn{2}{|c|}{ NSTEMI $(n=65)$} & \multirow[t]{2}{*}{$p$ value* } \\
\hline & $\mathrm{n}$ & $\%$ & $\mathrm{~N}$ & $\%$ & \\
\hline Smoking/Tobacco consumption & 49 & 70 & 41 & 63.1 & $0.040^{\mathrm{S}}$ \\
\hline Dyslipidemia & 44 & 62 & 32 & 42.1 & $0.134 \mathrm{NS}$ \\
\hline Diabetes mellitus & 12 & 17.1 & 22 & 33.8 & $0.025^{S}$ \\
\hline Hypertension & 22 & 31.4 & 34 & 52.3 & $0.014^{S}$ \\
\hline Family history of CAD & 24 & 34.3 & 27 & 41.5 & $0.385 \mathrm{NS}$ \\
\hline Overweight (BMI $\geq 25.00-29.99$ ) & 40 & 57.1 & 42 & 64.6 & 0.374 NS \\
\hline
\end{tabular}

NS $=$ Not significant

$\mathrm{S}=$ Significant

${ }^{*}$ Chi-square test was done to measure the level of significance

Table-II

Comparison of Echocardiographic findings of the study population between groups $(n=135)$

\begin{tabular}{|c|c|c|c|c|c|}
\hline \multirow[t]{2}{*}{ Ejection Fraction (\%) } & \multicolumn{2}{|c|}{ STEMI $(\mathrm{n}=70)$} & \multicolumn{2}{|c|}{ NSTEMI(n=65) } & \multirow[t]{2}{*}{$p$ value* } \\
\hline & $\mathrm{n}$ & $\%$ & $\mathrm{~N}$ & $\%$ & \\
\hline Normal $(\geq 55 \%)$ & 2 & 2.9 & 35 & 53.8 & $0.001^{\mathrm{s}}$ \\
\hline Mild (45-54 \%) & 33 & 47.1 & 22 & 33.8 & \\
\hline Moderate (30-44 \%) & 35 & 50 & 8 & 12.3 & \\
\hline Mean $\pm S D$ & \multicolumn{2}{|c|}{$44.63 \pm 4.7$} & \multicolumn{2}{|c|}{$54.14 \pm 7.4$} & $0.001^{\mathrm{s}}$ \\
\hline Range & \multicolumn{2}{|c|}{$35-60$} & \multicolumn{2}{|c|}{ 35-68 } & \\
\hline Presence of RWMA & 70 & 100 & 40 & 61.5 & $0.001^{\mathrm{S}}$ \\
\hline
\end{tabular}

NS $=$ Not significant

$\mathrm{S}=$ Significant

${ }^{*}$ Chi-square test and unpaired t-test were done to measure the level of significance

Table-III

Comparison of vessel involvement in between study groups $(n=135)$

\begin{tabular}{|c|c|c|c|c|c|}
\hline \multirow[t]{2}{*}{ Involved vessels } & \multicolumn{2}{|c|}{ STEMI $(n=70)$} & \multicolumn{2}{|c|}{ NSTEMI $(n=65)$} & \multirow[t]{2}{*}{$p$ value* } \\
\hline & $\mathrm{n}$ & $\%$ & $\mathrm{n}$ & $\%$ & \\
\hline LMCA & 0 & 0 & 3 & 4.6 & $0.069 \mathrm{NS}$ \\
\hline LAD & 55 & 78.6 & 35 & 53.8 & $0.002^{s}$ \\
\hline LCX & 20 & 28.6 & 36 & 55.4 & $0.001 \mathrm{~s}$ \\
\hline $\mathrm{RCA}$ & 30 & 42.9 & 35 & 53.8 & $0.202 \mathrm{NS}$ \\
\hline
\end{tabular}

NS $=$ Not significant

$\mathrm{S}=$ Significant

${ }^{*}$ Chi-square test was done to measure the level of significance

Table-IV

Comparison of number of involved vessels in between study groups $(n=135)$

\begin{tabular}{|c|c|c|c|c|c|}
\hline \multirow[t]{2}{*}{ Number of involved vessels } & \multicolumn{2}{|c|}{ STEMI $(n=70)$} & \multicolumn{2}{|c|}{ NSTEMI $(n=65)$} & \multirow[t]{2}{*}{$P$ value* } \\
\hline & $\mathrm{n}$ & $\%$ & $\mathrm{~N}$ & $\%$ & \\
\hline LMCA & 0 & 0 & 3 & 4.6 & $0.069 \mathrm{NS}$ \\
\hline SVD & 44 & 62.9 & 18 & 27.7 & $0.001 \mathrm{~s}$ \\
\hline DVD & 19 & 27.1 & 23 & 35.4 & $0.301 \mathrm{NS}$ \\
\hline TVD & 6 & 8.6 & 14 & 21.5 & $0.034^{\mathrm{S}}$ \\
\hline Normal & 1 & 1.4 & 3 & 4.6 & $0.275^{N S}$ \\
\hline Non critical & 0 & 0 & 4 & 6.2 & $0.035^{\mathrm{s}}$ \\
\hline
\end{tabular}

NS $=$ Not significant

$\mathrm{S}=$ Significant

${ }^{*}$ Chi-square test was done to measure the level of significance 
Table I showing distribution of risk factors between the groups. There were statistically significant difference between the two groups in terms of smoking/tobacco consumption (70\% in STEMI group and $63.1 \%$ in NSTEMI group), diabetes mellitus (17.1\% in STEMI group and $33.8 \%$ in NSTEMI group) and hypertension (31.4\% in STEMI group and $52.3 \%$ in NSTEMI group) $(p<0.05)$

Table II shows normal EF was found only $2.9 \%$ patient in STEMI group but $53.8 \%$ patents in NSTEMI group. The mean EF of STEMI group was $44.63 \pm 4.7$ and $54.14 \pm 7.4$ in NSTEMI group. $100 \%$ patients had RWMA in STEMI group whereas $61.5 \%$ patients had RWMA in NSTEMI group. Analysis revealed there was statistically significant difference between two study groups $(p<0.05)$

There was statistically significant difference in LAD (78.6\% in STEMI group and $53.8 \%$ in NSTEMI group) and LCX (28.6\% in STEMI group and $55.4 \%$ in NSTEMI group) involvement between the two groups $(p<0.05)$

Table IV shows number of involved vessels among the study groups. SVD (62.9\% in STEMI group and $27.7 \%$ in NSTEMI group), TVD (8.6\% in STEMI group and $21.5 \%$ in NSTEMI group) and noncritical coronary artery lesion (6.2\% only in NSTEMI) had statistically significant difference between the two groups $(p<0.05)$. In case of STEMI multivessel involvement ( $\geq 2$ vessel involvement) was $35.7 \%$ and in case of NSTEMI it was $56.9 \%$

\section{Discussion:}

This study was conducted to see the differences in risk factors and angiographic profile in young patient with STEMI and NSTEMI. Considering inclusion and exclusion criteria total number of 135 patients were studied. Study population was divided into two groups, STEMI group and NSTEMI group. There were 70 patients in STEMI group and 65 patients in NSTEMI group. This study showed marked differences in between two study group in terms of risk factors and angiographic profile.

Considering distribution of age, it was found that highest percentage was in the group of $40-45$ years $(51.4 \%$ in STEMI \& $57 \%$ in NSTEMI) and lowest in age group of $25-$ 29 years $(4.3 \%$ in STEMI \& $3.7 \%$ NSTEMI). There were no statistically significant difference in age distribution pattern between groups ( $p$ value $>0.05$ ), which was consistent with previous study ${ }^{36}$.

Distribution of male patients in STEMI and NSTEMI group were $94.3 \%$ and $86.2 \%$ respectively and female patients were $5.7 \%$ in STEMI and $13.8 \%$ in NSTEMI group respectively. There were no statistically significant difference in sex distribution pattern between the groups
( $p$ value $>0.05$ ). $90.4 \%$ of the patients were male and $9.6 \%$ were female. This findings signify that young male have higher chance of developing MI than female. Similar result was found in a Bangladeshi study where $94.7 \%$ patients were male and $5.4 \%$ patient were female ${ }^{37}$. Maroszynska-Dmoch \& Wozakowska-Kaplon, Haque, et al. and Deora, et al. also found similar findings ${ }^{16,21,29}$.

Regarding distribution of risk factors in study population, smoking/tobacco consumption was $66.7 \%$, dyslipidemia was $56.3 \%$, hypertension was $42.5 \%$, diabetes mellitus was $25.2 \%$, family history of CAD was $37.8 \%$ and overweight was $60.7 \%$. In this study smoking/tobacco consumption was the most common risk factors. These findings were similar with the previous studies of Bangladesh. Haque, et al. (2010) has shown that smoking (64\%) was the most common risk factor in young patients, followed by dyslipidemia (50\%) and hypertension $(37.55 \%)^{21}$. In a study Malik, et al. (2016) has also shown similar findings ${ }^{37}$. Schoenenberger, et al. (2011) has also shown that smoking, family history of CAD, dyslipidemia and overweight were the most important cardiovascular risk factors in young patients 38. Maroszynska-Dmoch \& Wozakowska-Kaplon (2016); Tamrakar, et al. (2013) and Zimmeran, et al. (1995) also found similar findings in their studies $16,31,39$.

There were statistically significant difference between the two groups in terms of smoking/tobacco consumption, diabetes mellitus and hypertension $(p<0.05)$. Smoking/tobacco consumption was $70 \%$ in STEMI group and $63.1 \%$ in NSTEMI group. Dyslipidemia was found $62 \%$ in STEMI group and $42.1 \%$ in NSTEMI group. Diabetes mellitus was found $17.1 \%$ in STEMI group and $33.8 \%$ in NSTEMI group. Hypertension was found $31.4 \%$ in STEMI group and $52.3 \%$ in NSTEMI group. Family history of CAD was found $34.3 \%$ in STEMI group and $41.5 \%$ in NSTEMI group. Overweight was found $57.1 \%$ in STEMI group and $64.6 \%$ in NSTEMI group. Deora, et al. (2016) in their study found that hypertensive, diabetics and obese patients were significantly higher in the NSTEMI group. Smoking/tobacco consumption was identified as the most prevalent risk factor in patients in STEMI group (67.9\%) and NSTEMI group (69.9\%). In a study Song, et al. (2010) has found that hypertension (54.4\% vs $46.1 \%)$, diabetes mellitus (31.6\% vs $25.1 \%$ ) and dyslipidemia $(28.2 \%$ vs $18.2 \%)$ were significantly higher in NSTEMI group than STEMI group.

Regarding echocardiography, normal EF was found only $2.9 \%$ patient in STEMI group but $53.8 \%$ patents in NSTEMI group. The mean EF of STEMI group was $44.63 \pm 4.7$ and $54.14 \pm 7.4$ in NSTEMI group. $100 \%$ patients had RWMA 
in STEMI group whereas $61.5 \%$ patients had RWMA in NSTEMI group. Analysis revealed there was statistically significant difference between two study group $(p<0.05)$. Deora, et al. (2016) also found similar findings in their study 29 .

Considering distribution of involved vessels in this study, LAD $(66.7 \%)$ was the most commonly involved vessel followed by RCA (48\%) and LCX (41.5\%). LM (2.2\%) was the less commonly involved vessel. These findings are similar with the study done by Maroszynska-Dmoch and Wozakowska-Kaplon (2016); Haque, et al. (2010); Tamrakar, et al. (2013); Malik, et al. (2016) and Sharma, et al. (2014) in young patients ${ }^{16,27,31,37,40}$.

Regarding the involvement of vessels, Left main coronary artery disease (LMCA) was not found in STEMI group but $4.6 \%$ had LMCA disease in NSTEMI group. $78.6 \%$ and $53.8 \%$ had disease in LAD in STEMI and NSTEMI group respectively. $28.6 \%$ and $55.4 \%$ had LCX involvement in STEMI and NSTEMI group respectively. STEMI group had 42.9\% and NSTEMI group had 53.8\% RCA involvement. There was statistically significant difference in LAD and LCX involvement between the two groups $(p<0.05)$. Deora, et al. (2016) has shown similar findings that LAD involvement was more common among STEMI group of patients, while LCX and LMCA involvements were more common among NSTEMI group of patients and no significant difference was observed in case of RCA involvement ${ }^{29}$. Study done by Song, et al. (2010) also found similar findings ${ }^{27}$.

In this study the most common coronary lesion was SVD. Younger patients have higher prevalence of SVD (45.9\%) followed by DVD (31.1\%), TVD (14.8\%) and LMCA (2.2\%) which is similar to the study results of MaroszynskaDmoch \& Wozakowska-Kaplon (2016); Haque, et al. (2010); Tamrakar, et al. (2013); Malik, et al. (2016) and Schoeneberger, et al. (2011) 16,21,31,37,38.

Deora, et al. (2016) in their study found that SVD (56.6\%) was significantly higher in the STEMI group. The NSTEMI group had significantly higher TVD (10.5\%) and nonsignificantly higher DVD (15.3\%) and normal coronary arteries $^{29}$. In this study LMCA was not found in STEMI group but found $4.6 \%$ in NSTEMI group. SVD was found $62.9 \%$ in STEMI group and $27.7 \%$ in NSTEMI group, DVD was found $27.1 \%$ in STEMI group and $35.4 \%$ in NSTEMI group, TVD was found $8.6 \%$ in STEMI group and $21.5 \%$ in NSTEMI group. Normal coronary was found $1.4 \%$ and $3.6 \%$ in STEMI and NSTEMI group respectively. Non critical coronary lesion was found $6.2 \%$ only in NSTEMI group. SVD was significantly higher in STEMI group, TVD and noncritical coronary lesion were significantly higher in NSTEMI group.

\section{Conclusion:}

From this study it may be concluded that young male have higher chance of developing $\mathrm{MI}$ than female. Smoking/tobacco consumption is the most common risk factors in young patients, followed by overweight, dyslipidemia, hypertension, family history of CAD and diabetes mellitus. Smoking/tobacco consumption is significantly higher in STEMI patients, where as diabetes mellitus and hypertension are more common in NSTEMI patients. The frequency of SVD and involvement of LAD is significantly higher in young STEMI patients. In case of young NSTEMI patients frequency of TVD, noncritical coronary artery disease and involvement of LCX is significantly higher. The frequency of DVD and involvement of LMCA is also non-significantly higher in young NSTEMI patients. There is no significant difference regarding involvement of RCA.

\section{Limitations of the Study}

Although the result of this study is statistically significant and supports the hypothesis, there were some limiting factors which might affect the results:

- It was a single center study.

- Only traditional risk factors were included.

\section{Recommendations}

- Early identification and management of modifiable coronary risk factors are the keystone to prevent the occurrence of CAD and myocardial infarction at younger age.

- This study showed presence of more risk factors and more complex coronary artery lesion in young NSTEMI patients than young STEMI patients. So aggressive coronary risk factors modification and special attention to be taken for primary and secondary prevention of NSTEMI.

- Larger studies are required to establish specific associations between risk factors and angiographic profiles in young patients.

\section{References:}

1. Badran, H.M., Elnoamany, M.F., Khalil, T.S., Eldin, M.M.E. (2009) Age related alteration of risk profile, inflammatory response, and angiographic findings in patients with acute coronary syndrome. Clinical Medicine: Cardiology, 3, pp. 15-28. 
2. Gaziano, T.A., Bitton, A., Anand, S., Gessel, S.A. and Murphy, A. (2010) Growing epidemic of coronary heart disease in low- and middle-income countries. Current Problems in Cardiology, 35(2), pp. 72-115.

3. Sharma, M. and Ganguly, N.K. (2005) Premature coronary artery disease in Indians and its associated risk factors. Vascular Health and Risk Management, 1(3), pp. 217-225.

4. Murray, C.J. and Lopez, A.D. (1997) Mortality by cause for eight regions of the world: Global Burden of Disease Study. Lancet, 349, pp. 1269-1276.

5. Chadha, S.L., Radhakrishnan, S., Ramachandran, K., Kaul, U., Gopinath, N. (1990) Epidemiological study of coronary heart disease in urban population of Delhi. The Indian Journal of Medical Research, 92, pp. 424-430.

6. Enas, E.A., Yusuf, S. and Mehta. J.L. (1992) Prevalence of coronary artery disease in Asian Indians. The American Journal of Cardiology, 70, pp. 945-949.

7. Deedwania, P. and Singh, V. (2005) Coronary artery disease in South Asians: evolving strategies for treatment and prevention. Indian Heart Journal, 57, pp. 617-631.

8. Gupta, R. and Gupta, V.P. (1996) Meta-analysis of coronary heart disease prevalence in India. Indian Heart Journal, 48(3), pp. 241-245.

9. Yusuf, S., Hawken, S., Ôunpuu, S., Dans T., Avezum, A., Lanas, F., et al. x(2014) Cardiovascular risk and events in 17 low, middle and high-income countries. The New England Journal of Medicine, 371(9), pp. $818 " 827$.

10. Ebrahim, S., Pearce, N., Smeeth, L., Casas, J.P., Jaffar, S., Piot, P. (2013) Tackling noncommunicable diseases in low- and middleincome countries: is the evidence from high-income countries all we need? PLoS Medicine, 10(1), pp. $1-6$.

11. Malik, A., Islam, M.N., Zafar, A., Khan, A.K. and Ramizuddin, M. (1987) Clinical patterns of ischemic heart diseases and its association with some known risk factors. Bangladesh Heart Journal, 2, pp.1-9.

12. Malik, A. (1976) Congenital and acquired heart diseases: (A survey of 7062 persons). Bangladesh Medical Research Council Bulletin, 2(2), pp. 115-119.
13. Zaman, M.M., Ahmed, J., Choudhury, S.R., Numan, S.M., Parvin, K., Islam, M.S. (2007) Prevalence of ischemic heart disease in a rural population of Bangladesh. Indian Heart Journal, 59(3), pp. 239241.

14. Islam, A.K. and Majumder, A.A. (2013) Coronary artery disease in Bangladesh: a review. Indian Heart Journal, 65(4), pp. 424-435.

15. Chowdhury, A.W., Alam, N., Khan, H.I.L.R., Sabah, K.M.N., Amin, M. G. (2015) The Pattern of Cardiac Disease at Coronary Care Unit of Dhaka Medical College Hospital. Cardiovascular Journal, 7(2), pp.119-122.

16. Maroszynska-Dmoch, E.M. and WozakowskaKaplon, B. (2016) Clinical and angiographic characteristics of coronary artery disease in young adults: a single centre study, KardiologiaPolska, 74(4), pp. 314-321.

17. Arzamendi, D., Benito, B., Tizon-Marcos, H., Flores, J., Tanguay, J.F., Ly, H., et al. (2011) Increase in sudden death from coronary artery disease in young adults. American Heart Journal, 161(3), pp. 574580.

18. Egred, M., Viswanathan, G. and Davis, G.K. (2005) Myocardial infarction in young adults. Postgraduate Medical Journal, 81, pp. 741-745.

19. Trehan, N., Kishore, S. and Rissam, H.S. (2001) Coronary Artery Disease in Young Indians - The Missing Link. Journal, Indian Academy of Clinical Medicine, 2(3) pp. $128-132$.

20. Shaw, J.E., Sicree, R.A. andZimmet, P.Z. (2010) Diabetes atlas: global estimates of the prevalence of diabetes for 2010 and 2030. Diabetes Research and Clinical Practice, 87, pp. 4-14.

21. Haque, A.F.M.S., Siddiqui, A.R., Rahman, S.M.M., Iqbal, S.A., Fatema, N.N., Khan, Z. (2010) Acute Coronary Syndrome in the Young - Risk Factors and Angiographic Pattern, Cardiovascular Journal, 2(2), pp. 175-178.

22. Patwary, M.S.R., Reza, A.Q.M., Akanda, M.A.K., Islam, A.M.M., Majumder, A.A.S., Mohibullah, A.K.M., et al. (2008) Risk factors and pattern of coronary artery disease in young patients with Acute Myocardial Infarction. University Heart Journal, 4(1).

23. World Health Organization. Non-Communicable Disease Risk Factor Survey Bangladesh 2010. [Cited 2013 Jul 3]. 
24. Heck, J.E., Marcotte, E.L., Argos, M., Parvez, F., Ahmed, A., Islam, T., et al. (2011) Betel quid chewing in rural Bangladesh: prevalence, predictors and relationship to blood pressure. International Journal of Epidemiology, 41, pp. 462-472.

25. Hanifi, S.A., Mahmood, S.S., Bhuiya, A. (2011) Smoking has declined but not for all: findings from a study in a rural area of Bangladesh. Asia Pacific Journal of Public Health, 23(5), pp. 662-671.

26. Hauner, H. (2002) Insulin resistance and the metabolic syndrome-a challenge of the new millennium. European Journal of Clinical Nutrition, 56 (suppl. 1), pp. s25-29.

27. Song, Y.B., Hahn, J.Y., Kim, J.H., Lee, S.Y., Choi, S.H., Choi, J.H., et al. (2010) Comparison of Angiographic and Other Findings and Mortality in Non-ST Segment Elevation versus ST-Segment Elevation Myocardial Infarction in Patients Undergoing Early Invasive Intervention, The American Journal of Cardiology, 106, pp. 13961403.

28. Sim, D.S., Kim, J.H. and Jeong, M.H. (2009) Differences in clinical outcomes between patients with ST-elevation versus non-ST-elevation acute myocardial infarction in Korea. Korean Circulation Journal, 39, pp. 297-303.

29. Deora, S., Kumar, T., Ramalingam, R., Manjunath, C.N. (2016) Demographic and angiographic profile in premature cases of acute coronary syndrome: analysis of 820 young patients from South India. Cardiovascular Diagnosis and Therapy, 6(3), pp. 193-198.

30. Prajapati, J., Joshi, H., Sahoo, S., Virpariya, K., Parmar, M., Shah, K. (2015)AGE-related differences of novel atherosclerotic risk factors and angiographic profile among gujarati acute coronary syndrome patients. Journal of Clinical and Diagnostic Research, 9(6), pp. 5-9.

31. Tamrakar, R., Bhatt, Y.D., Kansakar, S., Bhattarai, M., Shaha, K.B., Tuladhar, E., (2013) Acute Myocardial Infarction in Young Adults: Study of Risk factors, Angiographic Features and Clinical Outcome. Nepalese Heart Journal, 1(1), pp. 13-14.

32. Jamil, G., Jamil, M., AlKhazraji, H., Haque, A., Chedid, F., Balasubramanian, M., et al. (2013) Risk factor assessment of young patients with acute myocardial infarction. American Journal of Cardiovascular Disease, 3(3), pp. 170-174.

33. Chen, L., Chester, M. and Kaski, J.C. (1995) Clinical Factors and Angiographic Features Associated With Premature Coronary Artery Disease. Chest, 108(2), pp. 364-369.

34. Nafakhi, H.A.F. (2013) Coronary angiographic findings in young patients with coronary artery disease. International Journal of Collaborative Research on Internal Medicine \& Public Health, 5(1), p. 50.

35. Hassan, Z., Farooq, S., Nazir, N. and lqbal, K., (2014), Coronary Artery Disease in Young: A Study of risk Factors and Angiographic Characterization in the Valley of Kashmir. International Journal of Scientific and Research Publications, 4(7), pp. 1-7.

36. Gupta, S., Gupta, V.K., Gupta, R., Arora, S., Gupta, V. (2012) Demographic profile and prevalence of risk factors and their correlation with STEMI, NSTEMI and premature CAD in documented CAD patients, Journal of Preventive Cardiology, 1(4), p. 164-171.

37. Malik, F.-T.-N., Kalimuddin, M., Ahmed, N., Badiuzzzaman, M., Ahmed, M.N., Dutta, A., et al. (2016) AMI in very young (aged d"35 years) Bangladeshi patients: Risk factors \& coronary angiographic profile, Clinical Trials and Regulatory Science in Cardiology, 13, pp. 2-3.

38. Schoenenberger, A.W., Radovanovic, D., Stauffer, J.C., Windecker, S., Urban, P., Niedermaier, G., et al. (2011) Acute coronary syndromes in young patients: Presentation, treatment and outcome, International Journal of Cardiology, 148, pp. 301302.

39. Zimmerman, F.H., Cameron, A., Fisher, L.D., Grace, N.G. (1995) Myocardial Infarction in Young Adults: Angiographic Characterization, Risk Factors and Prognosis (Coronary Artery Surgery Study Registry), Journal of American College of Cardiology, 26(3), pp. 655-656.

40. Sharma, R., Bhairappa, S., Prasad S.R., Manjunath, C.N. (2014) Clinical Characteristics, Angiographic Profile and in Hospital Mortality in Acute Coronary Syndrome Patients in South Indian Population, Heart India, 2(3), pp. 65-69. 